\title{
COMPLETELY ARCHIMEDEAN SEMIRINGS
}

\author{
SUNIL K. MAITY ${ }^{1}$ \\ Department of Pure Mathematics, University of Calcutta \\ 35, Ballygunge Circular Road, Kolkata - 700019, India \\ e-mail: skmpm@caluniv.ac.in \\ AND \\ Rumpa Chatterjee \\ Department of Mathematics, University of Burdwan \\ Golapbag, Burdwan - 713104, West Bengal, India \\ e-mail: rumpachatterjee13@gmail.com
}

\begin{abstract}
In this paper we give a structural description of completely Archimedean semirings which is an extension of the structure theorem of completely Archimedean semigroups.
\end{abstract}

Keywords: completely simple semiring, completely Archimedean semiring, Rees matrix semiring, nil-extension, bi-ideal.

2010 Mathematics Subject Classification: 16A78, 20M07, 20 M10.

\section{REFERENCES}

[1] J.L. Galbiati and M.L. Veronesi, On quasi completely regular semigroups, Semigroup Forum 29 (1984) 271-275. doi:10.1007/BF02573335

[2] J.M. Howie, Introduction to the theory of semigroups (Academic Press, 1976).

[3] J.S. Golan, The Theory of Semirings with Applications in Mathematics and Theoretical Computer Science (Pitman Monographs and Surveys in Pure and Applied Mathematics, 54, Longman Scientific, 1992).

[4] M.K. Sen, S.K. Maity and K.P. Shum, On Completely Regular Semirings, Bull. Cal. Math. Soc. 98 (2006) 319-328.

\footnotetext{
${ }^{1}$ Corresponding author.
} 
[5] M.K. Sen, S.K. Maity and H.J. Weinert, Completely Simple Semirings, Bull. Cal. Math. Soc. 97 (2005) 163-172.

[6] M. Petrich and N.R. Reilly, Completely regular semigroups (Wiley, New York, 1999).

[7] S. Bogdanović, Semigroups with a system of subsemigroups (Novi Sad, 1985).

[8] S. Bogdanović and S. Milić, A nil-extension of a completely simple semigroup, Publ. Inst. Math. (Beograd) (N.S.) 36 (1984) 45-50.

[9] S.K. Maity and R. Ghosh, On Quasi Completely Regular Semirings, Semigroup Forum 89 (2014) 422-430.

doi:10.1007/s00233-014-9579-y

[10] S.K. Maity and R. Ghosh, Nil-extension of a Completely Simple Semiring, Discuss. Math. Gen. Alg. Appl. 33 (2013) 201-209.

doi:10.7151/dgmaa.1206

[11] S. Milić and V. Pavlović, Semigroups in which some ideal is a completely simple semigroup, Publ. Inst. Math. 30 (1982) 123-130.

Received 27 November 2017

Revised 28 March 2018

Accepted 11 April 2018 